\title{
Physical fitness, fatigue, and quality of life after liver transplantation
}

\author{
Berbke T. J. van Ginneken · Rita J. G. van den Berg-Emons • \\ Geert Kazemier · Herold J. Metselaar • \\ Hugo W. Tilanus $\cdot$ Henk J. Stam
}

Accepted: 23 February 2007 / Published online: 16 March 2007

(c) Springer-Verlag 2007

\begin{abstract}
Fatigue is often experienced after liver transplantation. The aims of this cross-sectional study were to assess physical fitness (cardiorespiratory fitness, neuromuscular fitness, body composition) in liver transplant recipients and to explore whether physical fitness is related to severity of fatigue. In addition, we explored the relationship between physical fitness and health-related quality of life. Included were 18 patients $1-5$ years after transplantation (aged $48.0 \pm 11.8$ years) with varying severity of fatigue. Peak oxygen uptake during cycle ergometry, 6-min walk distance, isokinetic muscle strength of the knee extensors, body mass index, waist circumference, skinfold thickness, severity of fatigue, and health-related quality of life were measured. Cardiorespiratory fitness in the liver transplant recipients was on average 16-34\% lower than normative values $(P \leq 0.05)$. Furthermore, the prevalence of obesity seemed to be higher than in the general population (17 vs. $10 \%)$. We found no deficit in neuromuscular fitness. Cardiorespiratory fitness was the only fitness component that was related with severity of fatigue $\left(r_{\mathrm{s}}=-0.61\right.$ to $\left.r_{\mathrm{s}}=-0.50, P \leq 0.05\right)$. Particularly cardiorespiratory fitness was related with several aspects of health-related quality of life $\left(r_{\mathrm{s}}=0.48\right.$ to $r_{\mathrm{s}}=0.70$,
\end{abstract}

B. T. J. van Ginneken ( $₫)$ · R. J. G. van den Berg-Emons .

H. J. Stam

Department of Rehabilitation Medicine,

Erasmus University Medical Center Rotterdam,

Dr. Molewaterplein 40, 3015 GD Rotterdam, The Netherlands

e-mail: b.vanginneken@erasmusmc.nl

G. Kazemier $\cdot$ H. W. Tilanus

Department of General Surgery,

Erasmus University Medical Center, Rotterdam, The Netherlands

H. J. Metselaar

Department of Gastroenterology and Hepatology,

Erasmus University Medical Center, Rotterdam, The Netherlands
$P \leq 0.05)$. Results of our study imply that cardiorespiratory fitness and body composition are impaired in liver transplant recipients and that fitness is related with severity of fatigue (only cardiorespiratory fitness) and quality of life (particularly cardiorespiratory fitness) in this group. These findings have implications for the development of rehabilitation programs for liver transplant recipients.

Keywords Liver transplantation $\cdot$ Fatigue $\cdot$ Peak oxygen uptake $\cdot$ Isokinetic muscle strength $\cdot$ Body composition

\section{Introduction}

Liver transplantation (LTx) is the only definitive treatment for end-stage liver disease. Since 1988, patient survival and liver function after LTx have improved markedly, due to improved technical expertise, better selection of patients, improved post-LTx management of complications, and improved immunosuppressive therapy (Adam et al. 2003). In Europe, LTx has achieved a 1-year survival rate of $82 \%$ (Burroughs et al. 2006).

Although studies have reported that quality of life improves after LTx (Gross et al. 1999; van der Plas et al. 2003), limitations in daily function still remain (Gross et al. 1999; van der Plas et al. 2003). Amongst these limitations, liver transplant recipients often experience fatigue (Aadahl et al. 2002; Belle et al. 1997; Leyendecker et al. 1993; van den Berg-Emons et al. 2006). Gross et al. (1999), and Belle et al. (1997) reported that, although the intensity of fatigue was reduced after LTx, fatigue remained the most distressing symptom 1 year after surgery. Leyendecker et al. (1993) found that 9 months after LTx, complaints of fatigue were more severe in the LTx group than in the general population. In a previous study, we found severe fatigue in $44 \%$ of 
patients up to 15 years after LTx, and these complaints did not decrease over time (van den Berg-Emons et al. 2006a).

Rehabilitation programs might be effective in reducing severity of fatigue after LTx, but, to develop appropriate programs, knowledge on the factors associated with fatigue after LTx is necessary. However, data on these factors are scarce. Aadahl et al. (2002) and van den Berg-Emons et al. (2006a) suggested that the fatigue experienced by liver transplant recipients is primarily physical, rather than psychological. Furthermore, van den Berg-Emons et al. (2006b) found that severe complaints of fatigue in liver transplant recipients are associated with low levels of everyday physical activity. A hypoactive lifestyle may lead to a negative spiral: hypoactivity leading to a reduction in physical fitness and deterioration of complaints of fatigue, leading to further hypoactivity.

Few studies have investigated the physical fitness of liver transplant recipients, but the limited data available suggest a reduced physical fitness after LTx (Beyer et al. 1999; Stephenson et al. 2001; Unnithan et al. 2001). Stephenson et al. (2001) found a 40-60\% lower maximal oxygen uptake than predicted in liver transplant recipients. Beyer et al. (1999) reported that, although the cardiovascular and neuromuscular fitness in liver transplant recipients improved after a supervised exercise program during the post-operative year, maximal oxygen uptake and muscle strength remained 10-20\% lower compared to healthy gender and age-matched individuals. Also in pediatric liver transplant recipients, deficits in cardiovascular fitness, and abdominal muscle strength have been reported (Unnithan et al. 2001).

It may be hypothesized that deficits in physical fitness in liver transplant recipients are associated with complaints of fatigue. Furthermore, deficits in physical fitness may lead to impaired health-related quality of life (HRQoL). However, to our knowledge, no studies are available on the relationships between these parameters in liver transplant recipients.

Because of the scarcity of studies on physical fitness and related parameters in liver transplant recipients, the present study assessed physical fitness (cardiorespiratory fitness, neuromuscular fitness, and body composition) in liver transplant recipients and explored whether physical fitness is related to severity of fatigue in this group. The relationship between physical fitness and HRQoL was also explored.

\section{Patients and methods}

\section{Patients}

To obtain a representative sample of liver transplant recipients with respect to fatigue, we recruited liver transplant recipients with varying severity of fatigue, according to the distribution of severity of fatigue as found in our previous study in 96 liver transplant recipients (van den Berg-Emons et al. 2006a). Severity of fatigue in this previous study ranged from 'no signs of fatigue' to 'most disabling fatigue', and was assessed with the Fatigue Severity Scale of Krupp et al. (1989) (see below). Inclusion criteria for the present study were: LTx between 1 and 5 years ago, sufficient knowledge of the Dutch language, and age between 18 and 65 years. Exclusion criteria were: multiorgan transplant recipients, severe comorbidity, and contra-indication for a progressive maximal cycle ergometer test. Of the original sample of 96 patients in the previous study (van den Berg-Emons et al. 2006a), 4 patients had died, 1 patient had emigrated, 53 patients were transplanted more than 5 years previously, and 10 patients were not eligible because of contra-indications for a maximal cycle ergometer test. Of the 28 eligible patients, 18 patients $(64 \%)$ agreed to participate. There were no significant differences in relevant characteristics between the patients who decided to participate and the non-participants. The study was approved by the Medical Ethics Committee of the Erasmus University Medical Center. Written informed consent was obtained from all subjects. Table 1 shows the characteristics of the study group.

\section{Measurements}

\section{Physical fitness: cardiorespiratory}

Cardiorespiratory fitness was measured with a progressive maximal aerobic test on a cycle ergometer (ER800, Jaeger Toennies, Breda, The Netherlands). The test was preceded

Table 1 Characteristics of the study group $(n=18)$

\begin{tabular}{|c|c|}
\hline Age (years) & $48.0 \pm 11.8$ \\
\hline \multicolumn{2}{|l|}{ Gender } \\
\hline Male & 11 \\
\hline Female & 7 \\
\hline \multicolumn{2}{|l|}{ Primary disease $(n)^{\mathrm{a}}$} \\
\hline Chronic & 17 \\
\hline Acute & 1 \\
\hline Time since transplantation (years) & $3.3 \pm 1.1$ \\
\hline \multicolumn{2}{|l|}{ Immunosuppressive agents ${ }^{\mathrm{b}}$} \\
\hline 1 & 16 \\
\hline 2 & 1 \\
\hline 3 & 1 \\
\hline \multicolumn{2}{|c|}{ Results are presented as mean \pm SD or numbers } \\
\hline \multicolumn{2}{|c|}{$\begin{array}{l}\text { a Chronic primary disease: cholestatic }(n=6) \text {, viral }(n=6) \text {, miscella- } \\
\text { neous }(n=5) \text {; acute primary disease: intoxication }(n=1)\end{array}$} \\
\hline
\end{tabular}


by a 1 -min warm-up period $(20 \mathrm{~W})$. The test started at $20 \mathrm{~W}$, and resistance was increased every minute by 15 or $20 \mathrm{~W}$, depending on the ability of the patients. Individual protocols were constructed such that the total exercise time ranged from 8 to $12 \mathrm{~min}$. The pedal rate was $60 \mathrm{rpm}$ and strong verbal encouragement was given during the test. The test was terminated when the subject voluntarily stopped due to exhaustion, or when the patient was unable to maintain the initial pedal rate. Gas exchange and heart rate (HR) were measured continuously using a breath-by-breath gas analysis system ( $\mathrm{K}_{4} \mathrm{~b}^{2}$, COSMED, Rome, Italy). Subjective strain was measured immediately after the final stage by the Borg Category Scale for Rating of Perceived Exertion (Borg 1982). Patients were asked to indicate how strenuous they had experienced the test by giving a number from 0 (no effort at all) to 10 (maximal effort). Cardiorespiratory fitness was defined as the mean oxygen uptake during the last $30 \mathrm{~s}$ of exercise $\left[V \mathrm{O}_{2 \text { peak }}\right.$, in $\mathrm{ml} \mathrm{kg} \mathrm{km}^{-1} \mathrm{~min}^{-1}$ and in $\mathrm{ml} \mathrm{kg}$ fat-free mass $\left.{ }^{-1} \min ^{-1}\left(\mathrm{ml} \mathrm{kg}_{\mathrm{FFM}}^{-1} \min ^{-1}\right)\right]$. In addition, the ventilatory anaerobic threshold (VAT, expressed as percentage of predicted $\left.V \mathrm{O}_{2 \text { peak }}\right)$ was estimated by the ventilatory equivalent method, when $V_{\mathrm{E}} / V \mathrm{O}_{2}$ and $\mathrm{PetO}_{2}$ increased while $V_{\mathrm{E}} / V \mathrm{CO}_{2}$ and $\mathrm{PetCO}_{2}$ remained stable (Reinhard et al. 1979; Wasserman et al. 1999).

Finally, patients performed the submaximal 6-min walk test (6MWT) (Guyatt et al. 1985). Patients were instructed to walk, not run, as far as they could along a 30-m marked tape in a hall during a 6-min period. Standardized encouragement was provided with the following phrases: "You are doing well" and "Keep up the good work". Patients were allowed to stop and rest during the test, but were instructed to resume walking as soon as they felt able to do so. The 6-min walk distance (6MWD) was registered.

\section{Physical fitness: neuromuscular}

Isokinetic muscle strength of the knee extensors was assessed in both legs by a Biodex ${ }^{\circledR}$ dynamometer (Shirley, New York, USA), recording strength as torque in $\mathrm{Nm}$. The patients were seated against a back-rest, firmly strapped at the hip and thigh. The rotational axis was aligned with the lateral femoral epicondyle. After five familiarization repetitions, isokinetic strength was measured at $60 \%$ with 5 maximal contractions and at $180 \%$ s with 15 maximal contractions. Strong verbal encouragement was given during the test. Peak torque (PT) was defined as the maximum torque generated by the patients throughout one series of repetitions at each velocity.

\section{Physical fitness: body composition}

Height and body mass were measured without shoes. Body mass was measured using a Cormier Paribel ${ }^{\circledR}$ weighing chair (FH Balances Cormier, Romainville, France). Body mass index (BMI, $\mathrm{kg} \mathrm{m}^{-2}$ ) was calculated from height and body mass. Waist circumference $(\mathrm{cm})$ was measured midway between the lowest rib and the iliac crest while standing. Thickness of four skinfolds (biceps, triceps, subscapular, suprailiaca region) was measured twice at the right side of the body with a Harpenden Skin-Fold Caliper (Burgess Hill, UK). The mean of the two measurements was used as representative for each site. Percentage body fat (BF) was predicted from skinfold thickness according to the method of Durnin and Womersley (1974).

\section{Severity of fatigue}

Severity of fatigue was assessed by the Dutch version of the Fatigue Severity Scale (FSS) (Krupp et al. 1989). The FSS is a self-administered questionnaire with answers ranging from 1 ('strongly disagree') to 7 ('strongly agree'). The mean score of the nine inquiries ranges from 1 ('no signs of fatigue') to 7 ('most disabling fatigue'). Internal consistency, reliability, validity, and sensitivity of the FSS have been established in several patient groups (Krupp et al. 1989; Merkies et al. 1999).

In addition to the FSS, severity of fatigue was assessed with a horizontal visual analogue scale (VAS). Patients were asked to mark the $100-\mathrm{mm}$ line according to how intense they had experienced fatigue during the last month ( 0 denotes 'no fatigue experienced' and 100 denotes 'the most severe fatigue') (ter Borg et al. 2004). Visual analogue scales have been found to yield reliable and valid data (Huskisson 1982; Scott and Huskisson 1979).

Health-related quality of life

HRQoL was assessed by the validated Dutch version (RAND-36) (van der Zee and Sanderman 1993) of the Medical Outcomes Study Short Form-36 (SF-36) (Ware and Sherbourne 1992). The SF-36 is a validated, selfadministered questionnaire used internationally to measure health status with respect to different dimensions: physical functioning, social functioning, role limitations due to physical problems, role limitations due to emotional problems, pain, mental health, vitality, general health perception, and change in perceived health during the last 12 months. All raw scores were converted to a $0-100$ scale, with higher scores indicating higher levels of functioning or well-being.

\section{Procedure}

On the day of the measurements, patients refrained from caffeine, nicotine, and heavy exercise. The order of the tests was standardized: patients started with the 6MWT, 
Table 2 Individual results on physical fitness in the 18 liver transplant recipients

\begin{tabular}{|c|c|c|c|c|c|c|c|c|c|c|}
\hline $\begin{array}{l}\text { Age (year/ } \\
\text { Gender) }\end{array}$ & $\begin{array}{l}\text { BMI } \\
\left(\mathrm{kg} \mathrm{m}^{-2}\right)\end{array}$ & $\begin{array}{l}\text { Waist } \\
(\mathrm{cm})^{\mathrm{a}}\end{array}$ & $\begin{array}{l}\text { Body } \\
\text { fat }(\%)^{b}\end{array}$ & $\begin{array}{l}V \mathrm{O}_{2 \text { peak }} \\
\left(\mathrm{ml} \mathrm{kg}^{-1}\right. \\
\left.\min ^{-1}\right)\end{array}$ & $\begin{array}{l}V \mathrm{O}_{2 \text { peak }} \\
\left(\mathrm{ml} \mathrm{kg}_{\mathrm{FFM}}^{-1}\right. \\
\left.\min ^{-1}\right)^{\mathrm{b}}\end{array}$ & $\begin{array}{l}\text { VAT }(\% \\
\text { predicted } \\
\left.V \mathrm{O}_{2 \text { peak }} \text { sed }\right)\end{array}$ & $\begin{array}{l}\text { VAT }(\% \\
\text { predicted } \\
\left.V \mathrm{O}_{2 \text { peak }} \text { recr }\right)\end{array}$ & $\begin{array}{l}\text { 6MWD } \\
(\mathrm{m})\end{array}$ & $\begin{array}{l}\text { PT extension } \\
60 \% \text { s }(\mathrm{Nm})\end{array}$ & $\begin{array}{l}\text { PT extension } \\
180^{\circ} / \mathrm{s}(\mathrm{Nm})\end{array}$ \\
\hline $56 / \mathrm{M}$ & 28.3 & 111.0 & 29.0 & 36.5 & 51.4 & 54.1 & 42.7 & 652 & 156.3 & 88.2 \\
\hline $52 / \mathrm{M}$ & 29.0 & & 32.7 & 16.7 & 24.8 & 49.1 & 38.9 & 428 & 101.8 & 73.1 \\
\hline $42 / \mathrm{F}$ & 22.8 & & 28.9 & 34.5 & 48.5 & 90.5 & 65.8 & 530 & 100.0 & 65.6 \\
\hline $60 / F$ & 38.4 & 118.5 & 42.0 & 13.1 & 22.5 & 43.6 & 32.5 & 495 & 101.9 & 78.6 \\
\hline $64 / \mathrm{M}$ & 29.7 & 103.5 & 30.6 & 21.7 & 31.3 & 77.4 & 55.4 & 430 & 99.9 & 62.6 \\
\hline $24 / F$ & 21.0 & 72.0 & 25.9 & 29.9 & 40.4 & 38.8 & 31.1 & 660 & 159.9 & 111.5 \\
\hline 46/M & 26.5 & 100.0 & 25.8 & 28.2 & 38.0 & 48.6 & 38.7 & 606 & 151.6 & 88.5 \\
\hline $63 / \mathrm{M}$ & 24.4 & & 20.5 & 20.9 & 26.4 & 69.4 & 49.7 & 410 & 74.4 & 44.8 \\
\hline $42 / \mathrm{M}$ & 34.9 & 132.0 & & 22.8 & & 30.9 & 25.8 & 513 & 145.9 & 118.3 \\
\hline $53 / \mathrm{F}$ & 23.9 & 77.5 & 30.1 & 23.1 & 33.0 & 108.6 & 64.8 & 465 & 40.0 & 35.7 \\
\hline $53 / \mathrm{M}$ & 25.9 & 99.6 & 23.6 & 20.7 & 27.1 & 56.7 & 42.6 & 510 & 149.3 & 96.8 \\
\hline $39 / \mathrm{M}$ & 23.7 & 87.0 & 17.4 & 31.2 & 37.8 & 51.5 & 43.5 & 547 & 169.0 & 111.8 \\
\hline $33 / \mathrm{M}$ & 24.0 & 88.0 & 19.8 & 35.1 & 43.7 & 67.9 & 59.9 & 510 & 155.9 & 116.9 \\
\hline $63 / F$ & 33.0 & 103.0 & 34.8 & 15.8 & 24.2 & 57.9 & 43.2 & 303 & 67.2 & 39.4 \\
\hline $45 / F$ & 26.8 & & 30.8 & 23.6 & 34.1 & 61.0 & 46.2 & 514 & 120.1 & 61.7 \\
\hline $39 / F$ & 18.7 & 75.0 & 22.7 & 30.2 & 38.1 & 56.2 & 46.8 & 600 & 115.9 & 67.9 \\
\hline $32 / \mathrm{M}$ & 22.9 & 91.0 & 20.4 & 25.0 & 31.4 & 43.4 & 38.3 & 576 & 180.4 & 124.6 \\
\hline $58 / \mathrm{M}$ & 25.1 & 99.0 & 25.0 & 18.5 & 24.6 & 48.6 & 37.9 & 495 & 128.6 & 91.9 \\
\hline
\end{tabular}

Abbreviations: BMI $\left(\mathrm{kg} \mathrm{m}^{-2}\right)$, body mass index; Waist $(\mathrm{cm})$, waist circumference; $V \mathrm{O}_{2 \text { peak }}\left(\mathrm{ml} \mathrm{kg}^{-1} \mathrm{~min}^{-1}\right)$, peak oxygen uptake per kg; $V \mathrm{O}_{2 \text { peak }}$ $\left(\mathrm{ml} \mathrm{kg}-1 \mathrm{FFM} \quad \min ^{-1}\right)$, peak oxygen uptake per kg fat-free mass; VAT (\% predicted $\left.V \mathrm{O}_{2 \text { peak }}\right)$, ventilatory anaerobic threshold as percentage of predicted $\mathrm{VO}_{2}$ peak; sed, sedentary normative values; recr, recreational normative values; 6MWD, 6-min walk distance; PT, peak torque

a Waist circumference: $n=14$, because of thickness of the skin at the place of the cicatrice in four patients

b Body fat and $V \mathrm{O}_{2 \text { peak }}: n=17$, because the thickness of the subscapular skinfold could not be measured reliably in one patient

followed by the questionnaires (completed under supervision of the researcher), body composition measurements, strength test, and finally the progressive maximal aerobic test. Exercise tests were performed under supervision of a physician. There were sufficient rest periods between the tests.

\section{Statistics}

Statistical analysis was performed using SPSS 10.1 for Windows (SPSS Inc., Chicago, IL, USA). Results are presented as mean \pm standard deviation (SD), range or numbers. Results on cardiorespiratory fitness were compared to normative values for sedentary persons and to normative values for people who exercise no more than 1-2 h a week (recreational) (Vos et al. 2001). Results on neuromuscular fitness were compared with the normative values of Akima et al. (2001) and 6MWD was compared with the normative values of Enright and Sherill in healthy adults aged 4080 years (1998). When patients were younger than 40 years, the normative values of Gibbons et al. (2001) were used. Obesity was defined as a BMI $\geq 30$ (World Health Organization 1989), a waist circumference $\geq 102 \mathrm{~cm}$ in men and $\geq 88 \mathrm{~cm}$ in women (Lean et al. 1995) or per- centage $\mathrm{BF} \geq 25 \%$ in men and $\geq 32 \%$ in women (Lohman 1992).

Differences in physical fitness between patients and normative values were tested with the non-parametric MannWhitney U Test. Relationships between physical fitness and severity of fatigue and between physical fitness and quality of life were explored using the non-parametric Spearman correlation coefficient $\left(r_{\mathrm{s}}\right)$. A probability value $\leq 0.05$ determined statistical significance. However, because of the relatively small study sample, also results on the $\alpha=0.10$ level are presented (indicating a trend).

\section{Results}

Physical fitness

Mean score on the Borg Scale was $6.3 \pm 2.2$, indicating that the patients experienced the maximal ergometer test on average as heavy to very heavy. The mean $\mathrm{HR}_{\max }$ was $90 \pm 10 \%$ of what was predicted (predicted $\mathrm{HR}_{\max }=220$ age) (Fox et al. 1971).

The individual results of the patients are presented in Table 2. Table 3 shows the cardiorespiratory fitness and 
Table 3 Cardiorespiratory fitness and neuromuscular fitness in the liver transplant group

\begin{tabular}{|c|c|c|c|}
\hline & LTx group & Norm values $^{\mathrm{a}}$ & $P$ \\
\hline \multicolumn{4}{|l|}{ Cardiorespiratory fitness } \\
\hline \multirow[t]{2}{*}{$V \mathrm{O}_{2 \text { peak }}\left(\mathrm{ml} \mathrm{kg}^{-1} \mathrm{~min}^{-1}\right)$} & $24.8 \pm 6.9$ & $29.4 \pm 7.4 \quad(\mathrm{sed})$ & $0.07^{\dagger}$ \\
\hline & & $37.5 \pm 6.7 \quad$ (recr) & $0.00 *$ \\
\hline \multirow[t]{2}{*}{$V O_{2 \text { peak }}\left(\mathrm{ml} \mathrm{kg}_{\mathrm{FFM}}^{-1} \min ^{-1}\right)^{\mathrm{b}}$} & $34.0 \pm 8.7$ & $41.0 \pm 7.8 \quad(\mathrm{sed})$ & $0.02^{*}$ \\
\hline & & $50.9 \pm 5.9 \quad$ (recr) & $0.00^{*}$ \\
\hline 6MWD (m) & $513.6 \pm 88.9$ & $609.6 \pm 97.6$ & $0.01 *$ \\
\hline \multicolumn{4}{|l|}{ Neuromuscular fitness } \\
\hline $\mathrm{PT}$ extension at $60^{\circ} / \mathrm{s}(\mathrm{Nm})$ & $123.2 \pm 38.7$ & $138.5 \pm 44.1$ & 0.22 \\
\hline $\mathrm{PT}$ extension at $180^{\circ} / \mathrm{s}(\mathrm{Nm})$ & $82.1 \pm 27.9$ & $86.1 \pm 30.1$ & 0.59 \\
\hline
\end{tabular}

Results are presented as mean \pm SD

Abbreviations: $V \mathrm{O}_{2 \text { peak }}\left(\mathrm{ml} \mathrm{kg}^{-1} \min ^{-1}\right)$, peak oxygen uptake per $\mathrm{kg}$; $V \mathrm{O}_{\text {2peak }}\left(\mathrm{ml} \mathrm{kg} \mathrm{FFM}_{\mathrm{FF}}^{-1} \mathrm{~min}^{-1}\right)$, peak oxygen uptake per $\mathrm{kg}$ fat-free mass; VAT ( $\%$ predicted $V \mathrm{O}_{2 \text { peak }}$ ), ventilatory anaerobic threshold as percentage of predicted $\mathrm{VO}_{2}$ peak; sed, sedentary normative values; recr, recreational normative values (people who exercise no more than $1-2 \mathrm{~h}$ a week); $6 M W D$ 6-min walk distance; PT, peak torque

a Vos et al. (2001), Enright and Sherill (1998), Gibbons et al. (2001), Akima et al. (2001)

b $n=17$, because the thickness of the subscapular skinfold could not be measured reliably in one patient

* Significant $(P \leq 0.05)$ difference between patients and normative values

$\dagger$ Difference between patients and normative values at the $\alpha=0.10$ level (trend)

neuromuscular fitness of the patients compared with normative values. $V \mathrm{O}_{2 \text { peak }}$ in $\mathrm{ml} \mathrm{kg}^{-1} \mathrm{~min}^{-1}$ was $15 \pm 22 \%$ $(P=0.07)$ and $34 \pm 15 \%(P=0.00)$ lower than normative values for, respectively, sedentary persons and those who exercise recreationally. $V \mathrm{O}_{2 \text { peak }}$ in $\mathrm{ml} \mathrm{kg}_{\mathrm{FFM}}^{-1} \mathrm{~min}^{-1}$ was $16 \pm 19.2 \%(P=0.02)$ and $33 \pm 14.8 \%(P=0.00)$ lower than normative values for, respectively, sedentary persons and those who exercise recreationally. 6MWD was $16 \pm 14 \%(P=0.01)$ lower than normative values. There was no significant deficit in neuromuscular fitness. Table 4 shows the body composition of the LTx group. According to the cut-off points for obesity based on BMI, waist circumference and percentage $\mathrm{BF}$, respectively 17,36 , and $41 \%$ of the patients were classified as obese.

Table 4 Body composition in the liver transplant group

\begin{tabular}{ll}
\hline Body composition & Mean $\pm \mathrm{SD}$ \\
\hline Body weight $(\mathrm{kg})$ & $80.6 \pm 18.3$ \\
Height $(\mathrm{m})$ & $1.74 \pm .11$ \\
Body mass index $\left(\mathrm{kg} \mathrm{m}^{-2}\right)$ & $26.6 \pm 5.0$ \\
Waist circumference $(\mathrm{cm})^{\mathrm{a}}$ & $96.6 \pm 16.8$ \\
Body fat $(\%)^{\mathrm{b}}$ & $26.9 \pm 6.4$
\end{tabular}

Results are presented as mean $\pm \mathrm{SD}$

a Waist circumference: $n=14$, because of thickness of the skin at the place of the cicatrice in four patients

b Body fat: $n=17$, because the thickness of the subscapular skinfold could not be measured reliably in one patient
Table 5 Spearman correlation coefficients for the relationships between fitness parameters and severity of fatigue as measured with the Fatigue Severity Scale (FSS) and the Visual Analogue Scale (VAS) in 18 liver transplant recipients

\begin{tabular}{|c|c|c|c|c|}
\hline \multirow[t]{3}{*}{ Physical fitness } & \multicolumn{4}{|l|}{ Fatigue } \\
\hline & \multicolumn{2}{|l|}{ FSS } & \multicolumn{2}{|l|}{ VAS } \\
\hline & Rs & $P$ & Rs & $P$ \\
\hline \multicolumn{5}{|l|}{ Cardiorespiratory fitness } \\
\hline$V \mathrm{O}_{2 \text { peak }}\left(\mathrm{ml} \mathrm{kg}^{-1} \min ^{-1}\right)$ & -0.40 & 0.10 & -0.52 & $0.03 *$ \\
\hline$\%$ of sedentary norm & -0.17 & 0.50 & -0.42 & $0.08^{\dagger}$ \\
\hline$\%$ of recreational norm & -0.32 & 0.20 & -0.53 & $0.03 *$ \\
\hline$V O_{2 \text { peak }}\left(\mathrm{ml} \mathrm{kg}_{\mathrm{FFM}}^{-1} \min ^{-1}\right)^{\mathrm{a}}$ & -0.43 & $0.08^{\dagger}$ & -0.51 & $0.04 *$ \\
\hline$\%$ of sedentary norm ${ }^{a}$ & -0.35 & 0.17 & -0.50 & $0.04 *$ \\
\hline$\%$ of recreational norm ${ }^{a}$ & -0.45 & $0.07^{\dagger}$ & -0.61 & $0.01 *$ \\
\hline VAT $\left(\%\right.$ predicted $V \mathrm{O}_{2 \text { peak }}$ sed $)$ & 0.22 & 0.38 & 0.03 & 0.92 \\
\hline VAT ( $\%$ predicted $V \mathrm{O}_{2 \text { peak }}$ recr) & 0.17 & 0.49 & -0.06 & 0.82 \\
\hline 6MWD (m) & -0.44 & $0.07^{\dagger}$ & -0.53 & $0.03 *$ \\
\hline$\%$ of norm & -0.25 & 0.32 & -0.52 & $0.03 *$ \\
\hline \multicolumn{5}{|l|}{ Neuromuscular fitness } \\
\hline PT extension at $60 \% \mathrm{~s}(\mathrm{Nm})$ & -0.39 & 0.11 & -0.31 & 0.22 \\
\hline$\%$ of norm & -0.15 & 0.56 & -0.28 & 0.27 \\
\hline $\mathrm{PT}$ extension at $180^{\circ} / \mathrm{s}(\mathrm{Nm})$ & -0.30 & 0.22 & -0.12 & 0.64 \\
\hline$\%$ of norm & 0.02 & 0.93 & 0.04 & 0.87 \\
\hline \multicolumn{5}{|l|}{ Body composition } \\
\hline Body mass index $\left(\mathrm{kg} \mathrm{m}^{-2}\right)$ & 0.03 & 0.91 & 0.06 & 0.82 \\
\hline Waist circumference $(\mathrm{cm})^{\mathrm{b}}$ & -0.07 & 0.82 & -0.06 & 0.83 \\
\hline Body fat $(\%)^{\mathrm{a}}$ & 0.32 & 0.21 & 0.15 & 0.58 \\
\hline
\end{tabular}

Abbreviations: $V \mathrm{O}_{2}$ peak $\left(\mathrm{ml} \mathrm{kg}^{-1} \mathrm{~min}^{-1}\right)$, peak oxygen uptake per $\mathrm{kg} ; \mathrm{VO}_{2}$ peak $\left(\mathrm{ml} \mathrm{kg} \mathrm{FFM}_{\mathrm{FF}}^{-1} \mathrm{~min}^{-1}\right)$, peak oxygen uptake per $\mathrm{kg}$ fat-free mass; VAT ( $\%$ predicted $V \mathrm{O}_{2 \text { peak }}$ ), ventilatory anaerobic threshold as percentage of predicted $\mathrm{VO}_{2}$ peak; sed, sedentary normative values; re$\mathrm{cr}$, recreational normative values (people who exercise no more than $1-$ $2 \mathrm{~h}$ a week); 6MWD, 6-min walk distance; PT, peak torque

${ }^{\text {a }} n=17$, because the thickness of the subscapular skinfold could not be measured reliably in one patient

b $n=14$, because of thickness of the skin at the place of the cicatrice in four patients

* Significant $(P \leq 0.05)$ correlation

$\dagger$ Correlation at the $\alpha=0.10$ level (trend)

\section{Relationships}

Table 5 shows the correlation coefficients between the physical fitness parameters and severity of fatigue as assessed with the FSS and VAS. None of the parameters of neuromuscular fitness or body composition were significantly related with severity of fatigue, assessed with either the FSS or the VAS.

$V_{\mathrm{O}_{2 \text { peak }}}$ in $\mathrm{ml} \mathrm{kg}_{\mathrm{FFM}}^{-1} \mathrm{~min}^{-1}$ (absolute and expressed as percentage of recreational normative values) and 6MWD (absolute) were related with severity of fatigue as assessed 
with the FSS at the $\alpha=0.10$ level (trend). With respect to the VAS, $V \mathrm{O}_{2 \text { peak }}$ in $\mathrm{ml} \mathrm{kg}^{-1} \mathrm{~min}^{-1}$ (absolute and expressed as percentage of recreational normative values), $V \mathrm{O}_{2 \text { peak }}$ in $\mathrm{ml} \mathrm{kg}-{ }_{\mathrm{FFM}}^{-1} \min ^{-1}$ (absolute and expressed as percentage of both sedentary and recreational normative values) and 6MWD (absolute and expressed as percentage of normative values) were significantly $(P \leq 0.05)$ correlated with severity of fatigue. $V \mathrm{O}_{2 \text { peak }}$ in $\mathrm{ml} \mathrm{kg}^{-1} \mathrm{~min}^{-1}$ as percentage of sedentary normative values was related with severity of fatigue as assessed with the VAS at the $\alpha=0.10$ level (trend). The VAT was not correlated with severity of fatigue, assessed with the FSS or the VAS.

Table 6 shows the correlation coefficients between physical fitness parameters and HRQoL. There were several significant correlations between physical fitness and HRQoL and particularly between cardiorespiratory fitness on the one hand and 'Physical functioning', 'Social functioning' and 'Vitality' on the other hand.

\section{Discussion}

This is the first study in which relationships between several aspects of physical fitness and severity of fatigue are explored after LTx. The study is an initial step in identifying factors that are associated with fatigue in liver transplant recipients. A limitation of this study may be that the sample was relatively small. However, we believe that this sample is representative for patients after LTx and that the study provides important information for the development of rehabilitation programs for liver transplant recipients.

\section{Physical fitness}

We found average deficits in $V \mathrm{O}_{2 \text { peak }}$ of $16-34 \%$, when we compared the results in the liver transplant recipients with normative values for, respectively, sedentary persons and those who exercise no more than 1-2 $\mathrm{h}$ a week. We believe that a value in between the sedentary and recreational normative values is representative for healthy Dutch persons of the same age as the liver transplant recipients that participated in our study. 6MWD was $16 \%$ lower than normative values. This subnormal level of cardiorespiratory fitness (both $V \mathrm{O}_{2 \text { peak }}$ and 6MWD) is in agreement with findings of previous studies (Beyer et al. 1999; Stephenson et al. 2001; Unnithan et al. 2001). Furthermore, the prevalence of obesity was higher in this study than in the general Dutch population; $17 \%$ of the patients had a BMI of more than 30 compared to $10 \%$ in the general Dutch population (Gezondheidsraad 2003).

Impaired cardiorespiratory fitness in liver transplant recipients may be due to the use of immunosuppressive medication, e.g. glucocorticoids and calcineurin inhibitors, which may influence both the cardiovascular system and skeletal muscles (Hokanson et al. 1995; Mercier et al. 1996). Immunosuppressive medication can also induce appetite stimulation and diabetes mellitus; this in association with emotional conditions can cause a change in eating habits (Correia et al. 2003; Hussaini et al. 1998). Furthermore, patients with primary biliary cirrhosis and some patients with other chronic liver disease are hypermetabolic. LTx in these patients may lead to a reduction in resting metabolic rate and can also cause an increase in BF (Hussaini et al. 1998; Richardson et al. 2001). Besides immunosuppressive medication and changes in appetite and metabolism, also deconditioning (both before and after transplantation) may contribute to the impaired cardiorespiratory fitness and body composition (Epstein et al. 1998; Grose et al. 1995). In a previous study we found that severe complaints of fatigue were associated with low levels of everyday physical activity in liver transplant recipients (van den Berg-Emons et al. 2006b).

Because of the immunosuppressive medication and deconditioning, we also expected a deficit in neuromuscular fitness. However, this was not demonstrated in the present study, in contrast to Beyer et al. (1999), who found a 10 $20 \%$ lower muscle strength in liver transplant recipients compared to age- and sex-matched sedentary individuals. They contributed this deficit to muscle weakness as a sideeffect of glucocorticoids.

The discrepancy between the findings of our study and those of Beyer et al. (1999) may be explained by the use of Tacrolimus instead of cyclosporine in the majority of our subjects. Tacrolimus is known to have less side effects than cyclosporine (Maes and Vanrenterghem 2004).

Stephenson et al. (2001) reported an early VAT in liver transplant recipients $\left(<45-50 \%\right.$ of the predicted $\left.V \mathrm{O}_{2 \max }\right)$ compared to $50-60 \%$ of the $V \mathrm{O}_{2 \max }$ in healthy persons found by Davis et al. (1997). They contributed this early anaerobic threshold in liver transplant recipients to the cyclosporine-induced decrease in mitochondrial oxygen consumption (2001). However, the European Respiratory Society (ERS Task Force 1997) reported that there is a wide range of normal predicted values (35-70\%). Therefore, it is difficult to indicate whether the VAT in our patients was reduced compared to normal $(58.6 \pm 18.9$ and $44.7 \pm 11.1 \%$ of predicted $V \mathrm{O}_{2 \text { peak }}$ for, respectively, sedentary persons and those who exercise recreationally).

\section{Physical fitness and severity of fatigue}

Although relationships between severity of fatigue (as measured with the FSS and VAS) and physical fitness were not univocal, this study demonstrates a relationship between cardiorespiratory fitness and severity of fatigue after LTx. 
Table 6 Spearman correlations coefficients for the relationships between physical fitness and health-related quality of life as assessed with the RAND-36 in 18 liver transplant recipients

\begin{tabular}{|c|c|c|c|c|c|c|c|c|c|}
\hline \multirow[t]{2}{*}{ Physical fitness } & \multicolumn{9}{|c|}{ RAND-36 domain } \\
\hline & PF & SF & Rlp & Rle & MH & VT & $\mathrm{BP}$ & $\mathrm{GH}$ & $\mathrm{CH}$ \\
\hline \multicolumn{10}{|l|}{ Cardiorespiratory fitness } \\
\hline$V O_{2 \text { peak }}\left(\mathrm{ml} \mathrm{kg}^{-1} \min ^{-1}\right)$ & 0.55 & - & - & - & - & - & - & - & - \\
\hline$\%$ of sedentary norm & - & 0.42 & - & - & - & 0.50 & - & - & - \\
\hline$\%$ of recreational norm & 0.48 & - & - & - & - & 0.51 & - & - & - \\
\hline$V O_{2 \text { peak }}\left(\mathrm{ml} \mathrm{kg}_{\mathrm{FFM}}^{-1} \min ^{-1}\right)^{\mathrm{a}}$ & 0.57 & 0.51 & 0.41 & - & - & - & - & - & - \\
\hline$\%$ of sedentary norm ${ }^{a}$ & - & 0.56 & - & - & - & 0.59 & - & 0.48 & - \\
\hline$\%$ of recreational norm ${ }^{a}$ & 0.46 & 0.58 & - & - & - & 0.58 & - & - & - \\
\hline VAT $\left(\%\right.$ predicted $V \mathrm{O}_{2 \text { peak }}$ sed $)$ & - & - & - & - & - & - & - & - & - \\
\hline VAT $\left(\%\right.$ predicted $V \mathrm{O}_{2 \text { peak }}$ recr $)$ & - & - & - & - & - & - & - & - & - \\
\hline 6MWD (m) & 0.67 & 0.57 & - & - & 0.53 & - & 0.54 & - & - \\
\hline$\%$ of norm & - & 0.70 & - & - & - & 0.51 & - & - & 0.44 \\
\hline \multicolumn{10}{|l|}{ Neuromuscular fitness } \\
\hline PT extension at $60^{\circ} / \mathrm{s}(\mathrm{Nm})$ & 0.44 & - & - & - & .41 & - & - & - & - \\
\hline$\%$ of norm & - & 0.68 & - & - & - & - & 0.56 & - & - \\
\hline $\mathrm{PT}$ extension at $180^{\circ} / \mathrm{s}(\mathrm{Nm})$ & - & - & - & - & - & - & 0.44 & - & - \\
\hline$\%$ of norm & - & 0.51 & - & 0.54 & - & - & 0.50 & - & - \\
\hline \multicolumn{10}{|l|}{ Body composition } \\
\hline Body mass index $\left(\mathrm{kg} \mathrm{m}^{-2}\right)$ & - & - & - & - & - & - & - & - & - \\
\hline Waist circumference $(\mathrm{cm})^{\mathrm{b}}$ & - & - & -0.49 & -0.41 & - & - & - & - & - \\
\hline Body fat $(\%)^{\mathrm{a}}$ & - & - & & - & - & - & - & - & \\
\hline
\end{tabular}

To enhance the clarity of the table, only significant correlation coefficients $(P \leq 0.05$, bold) or trends $(P<0.10$, not bold $)$ are presented

Abbreviations: $V \mathrm{O}_{2}$ peak $\left(\mathrm{ml} \mathrm{kg}^{-1} \mathrm{~min}^{-1}\right)$, peak oxygen uptake per $\mathrm{kg} ; V_{2}$ peak $\left(\mathrm{ml} \mathrm{kg}_{\mathrm{FFM}}^{-1} \mathrm{~min}^{-1}\right)$, peak oxygen uptake per kg fat-free mass; VAT $\left(\%\right.$ predicted $V_{2}$ peak $)$ ventilatory anaerobic threshold as percentage of predicted $V_{2}$ peak; sed, sedentary normative values; recr, recreational normative values (people who exercise no more than 1-2 h a week); 6MWD, 6-min walk distance; PT, peak torque; PF, physical functioning; SF, social functioning; Rlp, Role limitations physical; Rle, Role limitations emotional; MH, mental health; VT, vitality; BP, bodily pain; GH, general health perception; $\mathrm{CH}$, changes in health

a $n=17$, because the thickness of the subscapular skinfold could not be measured reliably in one patient

b $n=14$, because of thickness of the skin at the place of the cicatrice in four patients

Patients with more severe complaints of fatigue had larger deficits in cardiorespiratory fitness than patients with less severe complaints of fatigue. Although this cross-sectional study does not allow us to conclude that a reduced cardiorespiratory fitness results in fatigue (or vice versa), there may be an interaction between parameters: complaints of fatigue leading to decreased physical activity (van den Berg-Emons et al. 2006b) and decreased physical fitness, leading to further deterioration of complaints of fatigue. It may then be hypothesized that rehabilitation programs, aimed at enhancing cardiorespiratory fitness, can be effective in breaking through this negative spiral and (partly) reduce complaints of fatigue in this population. However, this hypothesis has to be confirmed in future randomized trials.

In contrast to our expectations, the present study indicates that other aspects of physical fitness, neuromuscular fitness and body composition, do not seem to be related with severity of fatigue after LTx. However, it should be realized that our study sample was relatively small and some of the studied relationships may have failed to show statistical significance.

Physical fitness and HRQoL

Previous studies on healthy persons indicate that physical activity, fitness, and body fatness are associated with HRQoL and mood (Han et al. 1998; Stewart et al. 2003). There are also indications that physical activity is related to HRQoL after LTx (Painter et al. 2001; van den BergEmons et al. 2006b). Therefore, we expected to find a relationship between physical fitness and HRQoL in our study group. In agreement with the study of Stewart et al. (2003) in healthy elderly subjects, we found several significant correlations between physical fitness (particularly cardiorespiratory fitness) and HRQoL in our liver transplant recipients. Patients with large deficits in physical fitness experienced worse HRQoL than patients with small deficits in physical fitness. However, in contrast with studies in healthy persons (Han et al. 1998; Stewart et al. 2003), we 
found only few relationships between body composition and HRQoL.

Our results on the relationships between physical fitness and HRQoL imply that rehabilitation programs aimed at improving physical fitness (particularly cardiorespiratory fitness) may consequently result in improved HRQoL, particularly in improved physical and social functioning, vitality, and bodily pain. However, these implications have to be confirmed in future randomized trials on the effects of such rehabilitation programs in liver transplant recipients.

\section{Conclusion}

Cardiorespiratory fitness in the liver transplant recipients was distinctly impaired and the prevalence of obesity was higher than in the general population; there were no indications that neuromuscular fitness is impaired after LTx. Based on the relationships we found between cardiorespiratory fitness and severity of fatigue, a rehabilitation program aimed at enhancing cardiorespiratory fitness may help in reducing complaints of fatigue after LTx. Such rehabilitation programs may also result in improved HRQoL.

Acknowledgments The authors thank the rehabilitation physicians of the Department of Rehabilitation Medicine (Erasmus MC) and Han van Nieuwenhuizen (Department of Rehabilitation Medicine, Erasmus MC), Elly Nijsen, Lara Elshove, Anneloes Wilschut (Department of Gastroenterology and Hepatology, Erasmus MC) and Tim Takken (Department of Pediatric Physical Therapy and Exercise Physiology, Wilhelmina Children's Hospital University Medical Center Utrecht) for their contributions to this study.

\section{References}

Aadahl M, Hansen BA, Kirkegaard P, Groenvold M (2002) Fatigue and physical function after orthotopic liver transplantation. Liver Transpl 8:251-259

Adam R, McMaster P, O'Grady JG, Castaing D, Klempnauer JL, Jamieson N, Neuhaus P, Lerut J, Salizzoni M, Pollard S, Muhlbacher F, Rogiers X, Garcia Valdecasas JC, Berenguer J, Jaeck D, Moreno Gonzalez E (2003) The European Liver Transplant Association Evolution of liver transplantation in Europe: Report of the European Liver Transplant Registry. Liver Transpl 9:1231-1243

Akima H, Kano Y, Enomoto Y, Ishizu M, Okada M, Oishi Y, Katsuta S, Kuno S (2001) Muscle function in 164 men and women aged 20-84 yr. Med Sci Sports Exerc 33:220-226

Belle SH, Porayko MK, Hoofnagle JH, Lake JR, Zatterman RK (1997) Changes in quality of life after liver transplantation among adults. National Institute of Diabetes \& Digestive \& Kidney Diseases (NIDDK): Liver Transplantation Database (LTD). Liver Transpl Surg 3:93-104

Beyer N, Aadahl M, Strange B, Kirkegaard P, Hansen BA, Mohr T, Kjaer M (1999) Improved physical performance after liver transplantation. Liver Transpl Surg 5:301-309

Borg GA (1982) Psychophysical bases of perceived exertion. Med Sci Sports Exerc 14:377-381
Burroughs AK, Sabin CA, Rolles K, Delvart V, Karam V, Buckels J, O'Grady JG, Castaing D, Klempnauer J, Jamieson N, Neuhaus P, Lerut J, de Ville de Goyet J, Pollard S, Salizzoni M, Rogiers X, Muhlbacher F, Garcia Valdecasas JC, Broelsch C, Jaeck D, Berenguer J, Gonzalez EM, Adam R (2006) 3-month and 12month mortality after liver transplant in adults in Europe: predictive models for outcome. Lancet 367:225-232

Correia MITD, Ordones Rego L, Soares Lima A (2003) Post-liver transplant obesity and diabetes. Curr Opin Clin Nutr Metab Care 6:457-460

Davis JA, Storer TW, Caiozzo VJ (1997) Prediction of normal values for lactate threshold estimated by gas exchange in men and women. Eur J Appl Physiol 6:157-164

Durnin JVGA, Womersley J (1974) Body fat assessed from total body density and its estimation from skinfold thickness measurements on 481 men and women aged from 16 to 72 years. Br J Nutr 32:77-97

Enright PL, Sherill DL (1998) Reference equations for the six-minute walk in healthy adults. Am J Respir Crit Care Med 158:13841387

Epstein SK, Ciubotaru RL, Zilberberg MD, Kaplan LM, Jacoby C, Freeman R, Kaplan MM (1998) Analysis of impaired exercise capacity in patients with cirrhosis. Dig Dis Sci 43:1701-1707

ERS Task Force on Standardization of Clinical Exercise Testing. European Respiratory Society (1997) Clinical exercise testing with reference to lung diseases: indications, standardization and interpretation strategies. Eur Respir J 10:2662-2689

Fox SM III, Naughton JP, Haskell WL (1971) Physical activity and the prevention of coronary heart disease. Ann Clin Res 3:404-432

Gezondheidsraad (2003) Overgewicht en obesitas [Dutch]. Den Haag: publication no. 2003/07

Gibbons WJ, Fruchter N, Sloan S, Levy RD (2001) Reference values for a multiple repetition 6-minute walk test in healthy adults older than 20 years. J Cardiopulm Rehab 21:87-93

Grose RD, Nolan J, Dillon JF, Errington M, Hannan WJ, Bouchier IA, Hayes PC (1995) Exercise-induced left ventricular dysfunction in alcoholic and non-alcoholic cirrhosis. J Hepatol 18:326-332

Gross CR, Malinchoc M, Ray Kim W, Evans RW, Wiesner RH, Petz JL, Crippin JS, Klintmalm GB, Levy MF, Ricci P, Therneau TM, Dickson ER (1999) Quality of life before and after liver transplantation for cholestatic liver disease. Hepatology 29:356-364

Guyatt GH, Sullivan J, Thompson PJ, Fallen EL, Pugsley SO, Taylor DW, Berman LB (1985) The 6-minute walk: a new measure of exercise capacity in patients with chronic heart failure. Can Med Assoc J 132:919-923

Han TS, Tijhuis MA, Lean ME, Seidell JC (1998) Quality of life in relation to overweight and body fat distribution. Am J Public Health 88:1814-1820

Hokanson JF, Mercier JG, Brooks GA (1995) Cyclosporine A decreases rat skeletal muscle mitochondrial respiration in vitro. Am J Respir Crit Care Med 151:1848-1851

Huskisson EC (1982) Measurement of pain. J Rheumatol 9:768-769

Hussaini SH, Oldroyd B, Stewart SP, Soo S, Roman F, Smith MA, Pollard S, Lodge P, O'Grady JG, Losowsky MS (1998) Effects of orthotopic liver transplantation on body composition. Liver 18:173-179

International Obesity Task Force (1989) Obesity: preventing and managing the global epidemic. Report of WHO consultation on obesity. World Health Organization, Geneva

Krupp LB, LaRocca NG, Muir-Nash J, Steinberg AD (1989) The fatigue severity scale. Application to patients with multiple sclerosis and systemic lupus erythematosus. Arch Neurol 46:11211123

Lean MEJ, Han TS, Morrison CE (1995) Waist circumference as a measure for indicating need for weight management. BMJ $311: 158-161$ 
Leyendecker B, Bartholomew U, Neuhaus R, Horhold M, Blumhardt G, Neuhaus P, Klapp BF (1993) Quality of life of liver transplant recipients. A pilot study. Transplantation 56:561-567

Lohman TG (1992) Advances in body composition assessment. Current issues in exercise science series. Human Kinetics Publishers, Champaign

Maes BD, Vanrenterghem YF (2004) Cyclosporine: advantages versus disadvantages vis-à-vis tacrolimus. Transpl Proc 36:40S-49S

Mercier J, Ville N, Wintrebert P, Caillaud C, Varray A, Albat B, Thevenet A, Prefaut C (1996) Influence of post-surgery time after cardiac transplantation on exercise responses. Med Sci Sports Exerc 28:171-175

Merkies ISJ, Schmitz PIM, Samijn JPA, van der Meche FGA, van Doorn PA (1999) Fatigue in immune-mediated polyneuropathies. Neurology 53:1648-1654

Painter P, Krasnoff J, Paul SM, Ascher NL (2001) Physical activity and health-related quality of life in liver transplant recipients. Liver Transpl 7:213-219

Reinhard U, Muller PH, Schmulling RM (1979) Determination of anaerobic threshold by the ventilation equivalent in normal individuals. Respiration 38:36-42

Richardson RA, Garden OJ, Davidson HI (2001) Reduction in energy expenditure after liver transplantation. Nutrition 17:585-589

Scott J, Huskisson EC (1979) Vertical or horizontal visual analogue scales. Ann Rheum Dis 38:650

Stephenson AL, Yoshida EM, Abboud RT, Fradet G, Levy RD (2001) Impaired exercise performance after successful liver transplantation. Transplantation 72:1161-1164

Stewart KJ, Turner KL, Bacher AC, DeRegis JR, Sung J, Tayback M, Ouyang P (2003) Are fitness, activity, and fatness associated with health-related quality of life and mood in older persons? J Cardiopulm Rehabil 23:115-121 ter Borg PCJ, van Os E, van den Broek WW, Hansen BE, van Buuren HR (2004) Fluvoxamine for fatigue in primary biliary cirrhosis and primary sclerosing cholangitis: a randomized controlled trial. BMC Gastroenterol 4:13-21

Unnithan VB, Veehof SHE, Rosenthal P, Mudge C, O'Brien TH, Painter P (2001) Fitness testing of pediatric liver transplant recipients. Liver Transpl 7:206-212

van den Berg-Emons R, van Ginneken B, Wijffels M, Tilanus H, Metselaar H, Stam H, Kazemier G (2006a) Fatigue is a major problem after liver transplantation. Liver Transpl 12:928-933

van den Berg-Emons R, Kazemier G, van Ginneken B, Nieuwenhuijsen C, Tilanus H, Stam H (2006b) Fatigue, level of everyday physical activity, and quality of life after liver transplantation. J Rehab Med 38:124-129

van der Plas SM, Hansen BE, de Boer JB, Stijnen T, Passchier J, de Man RA, Schalm SW (2003) Generic and disease-specific healthrelated quality of life in non-cirrhotic, cirrhotic and transplanted liver patients: a cross-sectional study. BMC Gastroenterol 3:3345

van der Zee KI, Sanderman R (1993) Het meten van de algemene gezondheidstoestand met de RAND-36: Een handleiding [Dutch]. Noordelijk Centrum voor Gezondheidsvraagstukken, Rijksuniversiteit Groningen. ISBN: 90-72156-60-9

Vos JA (2001) Ergometrie en Trainingsbegeleiding [Dutch]. Nederlands Paramedisch Instituut, Amersfoort, pp 112-128. ISBN 9073054-70-2

Ware JE, Sherbourne CD (1992) The MOS 36-item short form health survey. I. Conceptual framework and item selection. Med Care 30:472-481

Wassermann K, Hansen JE, Sue DY, Whipp BJ, Casaburi R (1999) Principles of exercise testing and interpretation. Lippincott Williams and Wilkins, Philadelphia 